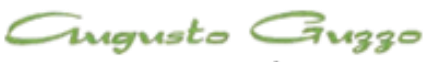

REVISTA ACADEMICA

\title{
A aderência dos relatórios de sustentabilidade das instituições financeiras ao modelo GRI
}

\author{
Ricardo Garrido Schwach', Robson Danúbio da Silva², César, Celso Machado \\ Júnior ${ }^{3}$, Angelo Palmisano 4 \\ Recebido em: 11/11/2014. Aprovado em: 06/12/2014. Disponibilizado em: 26/12/2014
}

\begin{abstract}
1. Ricardo Garrido Schwach, Mestrado Profissional de Administração em Governança Corporativa do Centro Universitário das Faculdades Metropolitanas Unidas.

2. Robson Danúbio da Silva César, Mestrado Profissional de Administração em Governança Corporativa do Centro Universitário das Faculdades Metropolitanas Unidas.

3. Celso Machado Júnior, Doutor em administração - e Professor do Programa de Mestrado Profissional de Administração em Governança Corporativa do Centro Universitário das Faculdades Metropolitanas Unidas.

4. Angelo Palmisano, Doutorado em Ciências Sociais Pontifícia Universidade Católica de São Paulo, Pró-Reitor Acadêmico e Professor do Programa de Mestrado Profissional de Administração em Governança Corporativa do Centro Universitário das Faculdades Metropolitanas Unidas.
\end{abstract}

\section{Resumo}

O ambiente corporativo evolui de forma determinante na criação de valor, a partir das boas práticas de Governança Corporativa. Neste contexto, os indicadores são utilizados para mensurar o desempenho empresarial e para auxiliar a tomada de decisão. Este artigo investiga a existência dos indicadores de desenvolvimento sustentável em instituições financeiras e a respectiva aderência destes aos modelos de indicadores propostos pelo GRI. A base de investigação se apoia em dados disponibilizados na forma de relatórios do Global Reporting Initiative (GRI), do Instituto Ethos (ETHOS) e de Indicadores de Sustentabilidade Empresarial (ISE). Realizou-se pesquisa em seis empresas do setor bancário, sendo três nacionais e três multinacionais. Os dados foram organizados de forma a possibilitar a comparação entre os diversos indicadores de sustentabilidade que as empresas utilizam. Esta abordagem possibilitou uma classificação de aderência destes indicadores segundo as três dimensões: econômica, social e ambiental. Os dados possibilitam evidências da existência de diversidade nos indicadores utilizados e baixo índice de aderência por estas empresas aos indicadores essenciais ao GRI.

Palavras-chave: Sustentabilidade; Modelos de Indicadores; Aderência; Governança Corporativa.

\begin{abstract}
The corporate environment evolves decisively in the creation of value, from the best practices of Corporate Governance. In this context, indicators are used to measure business performance and to aid decision making. Thus, this paper aims to investigate the existence of indicators of sustainable development in financial institutions and its adherence to
\end{abstract}


those proposed by the GRI models of indicators. The research is based on data available in the form of reports of the Global Reporting Initiative (GRI), the Ethos Institute (ETHOS) and Indicators of Corporate Sustainability Index (ISE). Does survey has been carried on in six companies in the banking sector, three national and three multinational. Data was organized in order to facilitate comparisons between different sustainability indicators that companies use. This approach made possible an adherence rating of these indicators according to three dimensions: economic, social and environmental. Data allow evidence of the existence of diversity in the indicators used and low rate of adherence GRI indicators.

Keywords: Sustainability; Models of Indicators; Adherence; Corporate Governance. 


\section{Introdução}

Há existência de sistemas de indicadores possibilita as organizações avaliarem suas atuações em aspectos relacionados ao meio ambiente, ao posicionamento financeiro, ao desempenho operacional, entre outros. Embora as organizações se apresentem bem estruturadas, os indicadores utilizados pelas empresas, podem divergir dos utilizados do praticados pelas demais empresas do mesmo setor. Esta divergência esta associada à adequação dos indicadores ao tipo de negócio, ao tamanho e cultura da empresa e aos impactos advindos de suas operações.

A importância dos indicadores reside no fato de se estabelecerem como métricas utilizadas para gerar informações quantitativas referentes às características ou atributos de um sistema ou fenômeno que esteja sendo observado, e auxiliar a tomada de decisão, de modo especial para o planejamento e monitoramento dos objetivos (KRAJNC; GLAVIC, 2005; BELLEN, 2005; CSD, 2002). Vale destacar que o estabelecimento dos indicadores ocorre em etapas específicas, tais como: seleção e combinação dos itens, avaliação de suas relações empíricas e validação do indicador (BABBIE, 1989). Neste contexto, os indicadores não devem ser resultantes da casualidade, mas sim parâmetros de monitoramento da execução do planejamento organizacional.

O mercado de capitais necessita de informações precisas para desenvolver de forma eficiente e efetiva as análises de desempenho das empresas. No entanto, em alguns casos é possível observar empresas que apresentam escassez de informações para o mercado de capitais, não atendendo a crescente demanda por maior transparência corporativa nas áreas que envolvem a linha das três dimensões: econômica, social e ambiental. Segundo Tinoco (2010) a solidez das empresas não resulta apenas dos indicadores econômico-financeiros, mas também do seu desempenho social e ambiental. Nesse sentido, o autor aponta o Global Reporting Initiative (GRI) como uma importante ferramenta para as empresas divulgarem o desempenho de uma atuação sustentável. Vale destacar, ainda no Brasil a existência de dois importantes relatórios que contemplam informações voltadas à sustentabilidade: os Indicadores de Sustentabilidade Empresarial (ISE) e do Instituto Ethos (ETHOS) este mais voltado à responsabilidade social das empresas.

Apesar de o GRI fornecer diretrizes para divulgação do desempenho das empresas. $\mathrm{O}$ nível de detalhamento dos relatórios gerados pode variar de empresa para empresa, pois as informações fornecidas refletem diferentes modelos de gestão e opiniões sobre o que é apropriado ser reportado. Esses documentos denominados como relatórios de sustentabilidade se materializam na principal ferramenta de comunicação do desempenho das empresas, e são voltados a medir e certificar as empresas com parâmetros que vão além da questão da transparência e da boa governança corporativa.

Amato Neto (2011) alerta sobre a grande importância de utilizar dados corretos na elaboração dos indicadores, evitando que tomadas decisões sejam baseadas em indicadores inadequados ou errados. Assim, os IdSs devem fazer parte dos processos da empresa, e relacionados às características especificas do negócio. Os indicadores têm como função apoiar a avaliação de metas e processos, identificando se os mesmos serão cumpridos, ou não. A utilização adequada do IdS depende do entendimento de como essas ferramentas são construídas. Os IdSs representam uma ferramenta de medição ambiental com base na comparação entre a situação presente e a situação sustentável adequada, que posicionando até que ponto os 
objetivos de sustentabilidade são atendidos (RAGAS et al., 1995).

Benites e Polo (2013) consideram que através dos relatórios de sustentabilidade é possível, para a empresa, apresentar por meio de seus indicadores o desempenho econômico, ambiental e social da sua gestão. Entretanto, os autores apontam o modelo de relatório da Global Reporting Initiative (GRI) como o mais completo e mundialmente difundido, pois este se propõe a medir e certificar as empresas com parâmetros que expressem o impacto de suas atividades na sociedade e no meio ambiente.

Dentre as mais diversas atividades econômicas em que se enquadram as empresas este estudo estabelece foco de atenção nas instituições financeiras, mais precisamente nos bancos que atuam no Brasil. Apesar de identificarmos tanto bancos nacionais quanto estrangeiros atuando no país, o que possibilita uma grande diversidade de modelos de gestão, todas as instituições estão sancionadas as leis brasileiras e as regras estabelecidas pelo Banco Central brasileiro. Conjunto legal este, que tende a direcionar as instituições a utilizarem indicadores comuns para mostrar seu desempenho. É possível inferir que as instituições financeiras despertam interesse nos relatórios de sustentabilidade tanto por mostrar seu desempenho, quanto por analisar o desempenho das empresas que solicitam empréstimos financeiros. Nesse contexto, a apresentação de relatórios e indicadores ajustados a demanda da sustentabilidade pelas instituições financeiras, possui potencial para se estabelecer como referencial a ser utilizado pelos seus clientes.

Neste contexto, este estudo objetiva investigar a existência dos indicadores de desenvolvimento sustentável em instituições financeiras e a respectiva aderência destes ao modelo proposto pelo GRI. Para atendimento do objetivo proposto esta pesquisa apresenta este capitulo introdutório, e na sequência o referencial teórico, os métodos utilizados na investigação, a análise dos dados levantados que por sua vez está mediada pela respectiva discussão e finalmente a conclusão.

\section{Referencial Teórico}

Para identificação dos fatores relativos ao desenvolvimento sustentável (DS) tornouse necessária a criação de mecanismos e maneiras que apontem, indiquem, anunciem ou estimem os níveis e impactos das atividades humanas, bem como suas possíveis tendências de ocorrência. Para tanto, foram criados Índices e IdS (BELLEN, 2007).

Segundo Bellen (2005), os indicadores são importantes para a compreensão do significado operacional do conceito de DS, funcionando como ferramenta didática. Bessermam (2003) considera que eles auxiliam no processo de conhecimento da realidade e orientam ações governamentais, empresariais e sociais.

A partir da década de 1990, vários indicadores de sustentabilidade foram desenvolvidos, testados e utilizados por instituições internacionais e nacionais, como mostram os estudos de: Moldan e Billharz (1997); Meadows (1998); Hardi e Zdan (2000); Deponti (2002); Hilson e Basu (2003); Becker (2004); e Bellen (2005), entre outros. Estes estudos apontavam para a necessidade de aferir a evolução do desenvolvimento sustentável. Os novos indicadores adicionaram a dimensão ambiental aos tradicionais indicadores econômicos e sociais, auxiliando os tomadores de decisões a avaliar os resultados e planejar programas públicos ou privados, dentro dessa nova perspectiva.

$\mathrm{O}$ uso de indicadores possibilitou evidenciar aos investidores quais empresas estão comprometidas com a responsabilidade 
socioambiental. Essa tendência começou em 1999, quando a Bolsa de Valores de Nova York apresentou o Dow Jones Sustainability Index (DJSI). Em seguida, vieram o FTSE4good, em 2001, de Londres; o Socially Responsible Index (SRI), de Johanesburgo, em 2002; e o Índice de Sustentabilidade Empresarial (ISE) da Bolsa de Valores de São Paulo - Bovespa, em 2005. Todos com o objetivo comum de servir de guia para o investidor escolher as empresas que não apenas apresentam rentabilidade positiva e geram dividendos, mas que também estão comprometidas com a responsabilidade socioambiental. Embora as organizações se apresentem bem estruturadas, os indicadores podem favorecer aspectos específicos: econômicos, sociais ou ambientais. Contexto no qual este estudo se insere ao apresentar os indicadores corporativos pelo Global Reporting Initiative (GRI).

O Modelo GRI tem como objetivo contribuir para a melhoria dos relatórios de sustentabilidade emitidos pelas organizações e estimular a adoção voluntária de indicadores com maior qualidade, rigor e aplicação global, para tornar tal prática mais harmonizada internacionalmente. Os Indicadores Ethos de Responsabilidade Social Empresarial (RSE), representam esforço do Instituto Ethos em oferecer às empresas uma ferramenta que as auxilie no processo de aprofundamento de seu comprometimento com a responsabilidade social e com o desenvolvimento sustentável. No contínuo desenvolvimento de indicadores para auxiliar as empresas, destaca-se também o ISE que foi desenvolvido com apoio do Instituto ETHOS e do GRI e tem se consolidado como uma ferramenta objetiva para comparar o desempenho de empresas listadas na BM\&F BOVESPA. Empresas estas que se destacam por possuírem alinhamento estratégico com a sustentabilidade, além da adoção de práticas que contribuem para o DS (Bovespa, 2011).

\subsection{Indicadores ETHOS}

Os indicadores ETHOS de RSE foram definidos pelo Instituto ETHOS, uma organização sem fins lucrativos que tem o objetivo de mobilizar, sensibilizar e ajudar as empresas a gerir seus negócios de forma socialmente responsável, tornando-as parceiras na construção de uma sociedade justa e sustentável (ETHOS, 2009).

O Instituto Ethos, por sua vez, promove a RSE como forma de gestão definida pela relação ética e transparente da empresa com os públicos com os quais ela se relaciona e pelo estabelecimento de metas empresariais que impulsionem o desenvolvimento sustentável da sociedade. Propõe um conjunto de 40 indicadores organizados em sete temas: Valores, Transparência e Governança; Meio Ambiente; Público Interno; Fornecedores; Consumidores e Clientes; e Comunidade e Governo e Sociedade (ETHOS, 2009).

A RSE implica práticas de diálogo e engajamento da empresa com todos os públicos ligados a ela, a partir de um relacionamento ético e transparente. Entre essas práticas estão às iniciativas das grandes empresas em estimular suas cadeias de fornecedores e clientes a também considerar os princípios da RSE em sua gestão.

A adoção dessas práticas possibilita o controle dos riscos e oportunidades de negócio e permite que não só a empresa, mas também sua cadeia de valor possam utilizar estratégias e ferramentas rumo à gestão socialmente responsável. Ferramentas que contribuam para o acompanhamento dos resultados na medição de até que ponto seus esforços estão atendendo seu objetivo de contribuir com o DS. 
Por meio do sistema dos Indicadores Ethos, as empresas preenchem um questionário e enviam suas respostas para o Instituto Ethos, onde os dados são processados, transformados em pontuação e notas e apresentados nos Relatórios de Diagnóstico. Tal contexto permite a cada empresa comparar seus indicadores, por meio de tabelas e gráficos, com o grupo de benchmarking (as dez empresas com as melhores notas) e com a média do grupo de empresas que responderam ao questionário no mesmo período.

No entanto, as organizações que quiserem acompanhar a gestão da responsabilidade social de seus fornecedores e clientes podem solicitar às informações ao Sistema Ethos desde que obtenham acesso e consentimento da empresa solicitada.

\subsection{Indicadores ETHOS e ISE}

O Índice de Sustentabilidade Empresarial (ISE) foi estruturado em 2005 pela Bolsa de Valores de São Paulo (Bovespa) em conjunto com outras instituições (Associação Brasileira das Entidades Fechadas de Previdência Complementar (ABRAPP), Associação Nacional dos Bancos de Investimento (ANBID), Associação dos Analistas e Profissionais de Investimento do Mercado de Capitais (APIMEC), Instituto Brasileiro de Governança Corporativa (IBGC), International Finance Corporation (IFC), Instituto ETHOS, com o propósito de ser um benchmark de empresas que se destacam em promover boas práticas sustentáveis e possuem comprometimento com Responsabilidade Social Corporativa (RSC) e sustentabilidade empresarial (TEIXEIRA; NOSSA; FUNCHAL, 2011). Porter e Kramer (2006) sugerem que a RSC faça parte da estratégia e, assim, usufruída como fonte de vantagem competitiva no intuito de melhorar o desempenho da empresa.
Estudos apontam evidências de que a RSC traz benefícios que são consistentes com os interesses de maximizar o bem estar do acionista no sentido de aumentar o valor presente dos fluxos de caixa futuros (MACKEY; MACKEY; BARNEY, 2007).

A evolução dos conceitos e definições da RSC, de acordo com Carroll (1999), ocorreu ao longo de décadas e se apresenta ainda hoje sob diversas variações. Desde os anos de 1930, auxiliou o "homem de negócios" a obter uma melhor compreensão, do novo sentido dessa responsabilidade.

Conforme a Bovespa (2009), a elaboração do ISE segue um padrão internacional dos principais IdSs do mundo (Dow Jones Sustainability Index - DJSI, Domini Social Index, FTSE4Good, índice de sustentabilidade da Bolsa de Johanesburgo etc.) dentro da dimensão Triple Bottom Line (TBL).

Com a finalidade de atender à crescente demanda por investimentos que fossem socialmente responsáveis e rentáveis, o ISE segue uma tendência das principais Bolsas de Valores do mundo, na premissa de que empresas que se preocupam com a sustentabilidade geram valor ao acionista no longo prazo.

Este índice tem por objetivo refletir o retorno de uma carteira teórica composta por ações de empresas com reconhecido comprometimento com a responsabilidade social e a sustentabilidade empresarial, promovendo as boas práticas no meio empresarial brasileiro. $O$ índice utiliza $O$ conceito do TBL, que avalia de forma integrada as dimensões econômicofinanceiras, sociais e ambientais das empresas.

De acordo com ISE, as empresas selecionadas para participarem da carteira do ISE precisam se destacar pelas estratégias e práticas adotadas, promovendo o DS 
conforme regras e critérios. Assim, são encaminhados questionários às empresas préselecionadas, com as 150 ações mais líquidas.

A estrutura do questionário está dividida nas dimensões tradicionais da sustentabilidade econômica, social e ambiental, além da governança corporativa, natureza do produto e da dimensão geral.

Como critérios de inclusão das empresas, serão integrados a carteira do ISE as ações que, além de serem uma das $150 \mathrm{com}$ maior negociação nos últimos 12 meses, devem atender simultaneamente aos seguintes critérios, conforme mostra a Bovespa (2009): Ter participado das negociações em, pelo menos, $50 \%$ dos pregões realizados nos 12 meses anteriores ao início da reavaliação da carteira; Atender aos critérios de sustentabilidade determinados pelo Conselho Deliberativo, divididos nas seguintes dimensões: geral, natureza do produto, governança corporativa, econômico-financeiro, ambiental e social. A Bovespa (2009) aponta que deixará de compor o ISE a empresa que: Deixar de cumprir qualquer um dos critérios de inclusão; Durante o período vigente da carteira, entrar em regime de recuperação judicial ou falência; No caso de oferta pública, resultando em retirada de circulação de parcela significativa de ações do mercado; Durante a vigência da carteira, deixarem de cumprir algum critério que altere significativamente seus níveis de sustentabilidade e responsabilidade social; Suspensão de negociação da respectiva ação por mais de 50 dias.

\subsection{Global Reporting Initiative - GRI}

A publicação de balanços sociais ou relatórios de sustentabilidade empresariais são úteis para demonstrar o desempenho das empresas (iniciativas, resultados, atitudes e investimentos), por meio do uso de vários indicadores ou parâmetros, em prol do desenvolvimento sustentável (MARIMON et al., 2012). Esses relatórios são demonstrativos anuais dos projetos, benefícios e ações sociais dirigidos a todos os stakeholders (públicos de interesse): empregados, investidores, governos, mercado, acionistas e comunidade (ETHOS, 2009).

Dentre as principais iniciativas para a elaboração e adesão das organizações empresariais aos padrões de publicação de relatórios de sustentabilidade destaca-se a GRI (BROWN; DE JONG; LEVY, 2009; LEVY; SZEJNWALD-BROWN; DE JONG, 2010), que é considerada como um dos mais consistentes esforços para consolidar as diversas iniciativas existentes para se chegar a um consenso sobre a avaliação de sustentabilidade empresarial (OLIVEIRA et al., 2009; BASSETTTO, 2010).

Fundada em 1997 por meio de uma ação conjunta da Coalizition for Environmentally Responsible (CERES) e do PNUMA (GRI, 2006a), a Global Reporting Initiative (GRI) é uma organização sem fins lucrativos baseada no desenvolvimento sustentável que criou uma conceituada estrutura para relatório de resultados das organizações focando o tripé da sustentabilidade nos aspectos econômico, social e ambiental (TINOCO, 2010).

No entanto, a GRI tem o objetivo de contribuir para a melhoria dos relatórios de sustentabilidade emitidos pelas organizações e estimular a adoção voluntária de indicadores com maior qualidade, rigor e aplicação global, para tornar tal prática mais harmonizada internacionalmente. Esses relatórios requerem a elaboração com base nos princípios da transparência, abrangência, relevância, verificabilidade, neutralidade, exatidão, objetividade, facilidade de compreensão, dentre outros (GRI, 2006a).

Segundo o GRI (2014), o indicador é uma informação qualitativa ou quantitativa 
sobre resultados ou consequências associadas à organização, comparável e que pode ser monitorada ao longo do tempo. Dessa forma, a GRI (2006a, p.5) define indicadores de desempenho como sendo "Informações comparáveis sobre o desempenho econômico, ambiental e social da organização."

Considerando a importância da compilação dos dados que resultarão nos indicadores, de forma a assegurar a coerência de informações comparáveis, bem como a coerência na interpretação dos indicadores de desempenho de forma geral, o GRI (2006a) ainda apresenta dois tipos de indicadores de desempenho: os essenciais e os adicionais. Considerados relevantes, os indicadores essenciais são aqueles identificados como de interesse $\mathrm{da}$ maioria dos stakeholders, enquanto os indicadores adicionais são utilizados para evidenciar práticas emergentes e abordam temas que podem ser importantes para apenas algumas empresas ou determinados segmentos.

Neste contexto sobre os indicadores apresentados no modelo GRI, relatórios de sustentabilidade são indispensáveis ferramentas para apresentação e transparência da mensuração da evolução das empresas quanto à gestão das três dimensões da sustentabilidade.

Elaborar relatórios de sustentabilidade consiste na prática de medir, divulgar e prestar contas, às várias partes interessadas, sobre o desempenho das organizações, visando atingir o objetivo do desenvolvimento sustentável. A expressão "elaboração de relatórios de sustentabilidade" é abrangente, e considerada sinônima de outros termos e expressões utilizados para descrever a comunicação dos impactos econômicos, ambientais e sociais. Um relatório de sustentabilidade deve fornecer uma declaração equilibrada e razoável do desempenho de sustentabilidade da organização nele representada, incluindo tanto as contribuições positivas, como as negativas.

Os relatórios de sustentabilidade baseados na estrutura definida pela GRI divulgam resultados e também consequências, que ocorreram durante $\mathrm{O}$ período relatado, no contexto dos compromissos, da estratégia e da abordagem de gestão adaptados pela organização. Os relatórios podem ser utilizados para outros objetivos, além dos seguintes:

- Benchmarking e avaliação do desempenho de sustentabilidade relativamente a leis, normas, códigos, padrões de desempenho e iniciativas voluntárias;

- Demonstração da forma como a organização influência e é influenciada por expectativas de desenvolvimento sustentável;

- Comparação do desempenho no âmbito de uma organização e entre diferentes organizações, ao longo do tempo.

Diversos estudos sobre os tipos de relatórios e indicadores corporativos de sustentabilidade têm sido realizados pelo mundo (LEVY; SZEJNWALD-BROWN; DE JON, 2010; BROWN; DE JONG; LEVY, 2009).

Globalmente, o modelo mais utilizado é o do GRI com os 79 indicadores propostos que envolvem questões sobre desempenho econômico, social eambiental (GRI, 2009). Assim, eles são divididos da seguinte forma:

Os nove indicadores de desempenho econômico envolvem aspectos sobre Desempenho Econômico Geral (4), Presença de Mercado (3) e Impactos Econômicos Indiretos (2). Os 30 indicadores de desempenho ambiental abordam aspectos sobre Consumo de Materiais (2); Energia (5); Água (3); Biodiversidade (5); Emissões, Efluentes e Resíduos (10); Produtos e Serviços (2); Conformidade (1); Transporte 
(1) e Geral, mas que contempla gastos e investimentos em proteção ambiental (1). Por sua vez, os 40 indicadores de desempenho social contemplam Práticas de Mão-de-Obra e Trabalho Decente (14); Direitos Humanos (9); Desempenho em relação à Sociedade (8) e Responsabilidade pelo Produto (9).

Para que um relatório seja reconhecido como baseado no GRI, exige-se uma auto declaração, segundo os critérios dos Níveis de Aplicação, que indicam quais os elementos da Estrutura do Relatório e das Diretrizes do GRI foram aplicados na elaboração do relatório de sustentabilidade. Os Níveis fornecem um ponto de partida para organizações que elaboram o relatório pela primeira vez e também reforçam a importância e valor de uma abordagem progressiva para a elaboração de relatórios que se expande ao longo do tempo (GRI, 2009).

Finalmente, após a confecção do relatório de sustentabilidade, a empresa pode auto-declarar um nível para seu relatório. A GRI (2006a) possibilita que a empresa relatora realize a sua própria avaliação face ao desempenho do conteúdo relatado. A GRI desenvolveu este sistema, denominado "níveis de aplicação GRI", com a intenção de proporcionar aos stakeholders um padrão de identificação quanto ao nível de transparência da utilização das diretrizes GRI aplicadas em um determinado relatório. Para os relatores, este processo pode servir como um medidor ou mesmo uma referência para expandir o grau de aplicabilidade da estrutura GRI em seus relatórios.

O sistema de níveis de aplicação da GRI (2006b) fornece três níveis divididos em A, B e $C$, sendo que o seguinte critério deverá ser respeitado: a) Para atender a um nível $\mathrm{C}$, em síntese, o relator deverá apresentar em sua estruturação do relatório um perfil organizacional, escopo e limite do relatório contendo o sumário de conteúdo da GRI e abordagem de governança corporativa. Atendendo a estas etapas, deverá responder, no mínimo, 10 indicadores de desempenho, sendo eles pelo menos um das áreas: econômica, ambiental e social; b) Para atender a um nível $\mathrm{B}$, além dos itens estruturais abordados no nível C, a organização deverá relatar a forma de gestão para cada categoria de indicador. Para este nível, é necessário que a empresa responda no mínimo a 20 indicadores, sendo estes pelo menos cada um das seguintes áreas: econômica, ambiental, direitos humanos, práticas trabalhistas, sociedade e responsabilidade pelo produto, etc. Para atender a um nível $\mathrm{A}$, além de todos os níveis estruturais abordados no nível B, a organização deverá responder os 49 indicadores essenciais ou respondendo ao indicador ou explicando o motivo de sua omissão.

Os níveis de aplicação da GRI (2006b), ainda possibilitam que a empresa apresente um ponto a mais em sua auto-avaliação $(+)$. Isso poderá ocorrer se a empresa submeterse a uma avaliação externa. Dessa forma, cada nível poderá apresentar-se da seguinte forma: $\mathrm{C}+, \mathrm{B}+\mathrm{e} \mathrm{A}+$.

\section{Metodologia}

Este trabalho efetuou uma análise descritiva, com abordagem quantitativa e qualitativa. Foi baseado em pesquisa documental, com utilização de dados secundários constantes na publicação de relatórios de sustentabilidade. Utilizou-se como base documental os relatórios divulgados pelas instituições financeiras no ano de 2013, com exceção do Banco Santander do qual se utilizou o relatório do ano de 2012, em face de não identificação da publicação do relatório pertinente ao regime de 2013. Os relatórios foram obtidos diretamente dos sites das instituições financeiras. Vale destacar, que a identificação 
dos mesmos ocorreu de forma simples e com baixo índice de dificuldade. Esta situação evidencia $\mathrm{O}$ interesse das instituições financeiras em divulgar e dar transparência dos resultados da sua gestão. Em posse dos relatórios analisou-se todos os indicadores publicados, e a respectiva adequação destes com ao do modelo do GRI.

A pesquisa documental pode ser parte integrante de um rol de instrumentos de um mesmo estudo ou o único instrumento de pesquisa. A pesquisa documental se justifica "[...] no momento em que se podem organizar informações que se encontram dispersas, conferindo-lhe uma nova importância como fonte de consulta" (LONGARAY et al., 2003, p. 89).

A pesquisa documental, na visão de Gil (2008, p. 52), apresenta as vantagens de que os "documentos constituem rica fonte de dados; como suscitam ao longo do tempo, torna-se a mais importante fonte de dados em qualquer pesquisa de natureza histórica e; não exige contato com o sujeito da pesquisa".

A coleta de dados por meio da pesquisa documental é a que usa informações que não receberam tratamento analítico. As fontes de coleta são diversificadas e dispersas, sendo os dados compilados pelo próprio pesquisador (LONGARAY et al., 2003).

Com relação aos seus objetivos este estudo caracteriza-se como exploratório e descritivo. Sua natureza exploratória consistiu na verificação e compreensão dos critérios para participação e seleção no ISE, enquanto na fase descritiva buscou-se descrever os dados coletados na pesquisa através das empresas que disponibilizam os relatórios de sustentabilidade.

Para Gil (2010), a pesquisa exploratória busca desenvolver, esclarecer e modificar conceitos e idéias para a formulação de novas abordagens num momento posterior. Cervo e Bervian (2002, p. 69) afirmam que "[...] os estudos exploratórios não elaboram hipóteses a serem testadas no trabalho, restringindo-se a definir objetivos e buscar mais informações sobre determinado assunto de estudo".

De acordo com Andrade (2002) a pesquisa descritiva tem como preocupação observar, registrar, analisar, classificar e interpretar os fatos, sem realizar nenhuma interferência. Rudio (2003) salienta que esse tipo de pesquisa envolve atividades como levantamento bibliográfico, pesquisa documental, questionários e entrevistas, com o objetivo de ampliar o conhecimento sobre o tema e descrever o fenômeno estudado.

\section{Apresentação e Análise dos Dados}

Conforme apontado na plataforma teórica, os relatórios de sustentabilidade das empresas devem apresentar indicadores de cunho econômico, social e ambiental. De acordo com o propósito da pesquisa, nos tópicos a seguir serão descritos e analisados os resultados da investigação documental realizada nos relatórios das empresas selecionadas para a avaliação.

Os resultados da pesquisa são apresentados e no final de cada tópico, quando apropriado, é realizada a análise e discussão apoiada no referencial teórico. Assim, utilizando-se de dados quantitativos descritivos, procurou-se explicar os indicadores de sustentabilidade das empresas no segmento finanças que foram apresentados em seus próprios Relatórios de Sustentabilidade.

Considerando a metodologia adotada para o presente estudo e com a finalidade de facilitar a demonstração e análise dos dados, escalas foram elaboradas, classificadas e são apresentadas na Tabela 1 , a seguir: 
Tabela 1 - Aderência das instituições financeiras aos indicadores do GRI

\begin{tabular}{|c|c|c|c|c|c|c|c|c|c|}
\hline \multirow[b]{3}{*}{ Empresas } & \multicolumn{9}{|c|}{ INDICADORES } \\
\hline & \multicolumn{3}{|c|}{ Econômico } & \multicolumn{3}{|c|}{ Social } & \multicolumn{3}{|c|}{ Ambiental } \\
\hline & Adere & $\begin{array}{l}\text { Não } \\
\text { Adere }\end{array}$ & $\begin{array}{c}\text { Não } \\
\text { apresentou }\end{array}$ & Adere & $\begin{array}{l}\text { Não } \\
\text { Adere }\end{array}$ & $\begin{array}{c}\text { Não } \\
\text { apresentou }\end{array}$ & Adere & $\begin{array}{l}\text { Não } \\
\text { Adere }\end{array}$ & $\begin{array}{c}\text { Não } \\
\text { apresentou }\end{array}$ \\
\hline $\begin{array}{l}\text { Banco do } \\
\text { Brasil }\end{array}$ & $0.9 \%$ & $0.7 \%$ & $0.0 \%$ & $7.0 \%$ & $1.8 \%$ & $0.0 \%$ & $4.0 \%$ & $2.2 \%$ & $0.0 \%$ \\
\hline Bradesco & $0.9 \%$ & $0.0 \%$ & $0.7 \%$ & $4.8 \%$ & $0.0 \%$ & $4.0 \%$ & $0.9 \%$ & $0.0 \%$ & $5.3 \%$ \\
\hline Citibank & $0.9 \%$ & $0.0 \%$ & $0.7 \%$ & $3.5 \%$ & $0.0 \%$ & $5.3 \%$ & $1.5 \%$ & $0.0 \%$ & $4.8 \%$ \\
\hline HSBC & $0.7 \%$ & $0.0 \%$ & $0.9 \%$ & $4.9 \%$ & $0.0 \%$ & $3.8 \%$ & $2.6 \%$ & $0.0 \%$ & $3.7 \%$ \\
\hline $\begin{array}{l}\text { Itaú } \\
\text { Unibanco }\end{array}$ & $0.4 \%$ & $0.0 \%$ & $1.3 \%$ & $2.9 \%$ & $0.0 \%$ & $5.9 \%$ & $2.0 \%$ & $0.0 \%$ & $4.2 \%$ \\
\hline Santander & $0.9 \%$ & $0.7 \%$ & $0.0 \%$ & $6.4 \%$ & $1.8 \%$ & $0.5 \%$ & $2.6 \%$ & $2.9 \%$ & $0.7 \%$ \\
\hline Total Geral & $4.76 \%$ & $1.47 \%$ & $3.66 \%$ & $29.49 \%$ & $3.66 \%$ & $19.60 \%$ & $13.55 \%$ & $5.13 \%$ & $18.68 \%$ \\
\hline
\end{tabular}

Fonte: dados da pesquisa investigados e selecionados pelos autores em São Paulo SP: 2014.

A Tabela 1 apresenta os indicadores de sustentabilidade nos aspectos econômicos, sociais e ambientais, qualificados pelas empresas. Os dados apontam a percentagem de aderência ou não aos indicadores. Para o levantamento destes dados, identificaram-se os indicadores apresentados nos relatórios das instituições financeiras, e os comparou com os propostos pelo GRI. O valor percentual apresentado expressa o índice de aderência do relatório da instituição financeira em relação ao proposto pelo GRI. Destaca-se que há casos em que os relatórios não apresentam os indicadores de determinada dimensão da sustentabilidade conforme proposto pelo GRI.

Os dados consolidados considerando todas as instituições apontam que a dimensão social foi a melhor abarcada pelos indicadores com uma aderência de 29,49\%. Na sequência aparece a dimensão ambiental com 13,55\% e com uma baixa aderência em relação às outras duas dimensões aparece a dimensão econômica com apenas 4,76\%.

Dentre os bancos analisados é possível observar que o Banco do Brasil e o Santander formam os únicos a apresentar indicadores não aderentes ao GRI nas três dimensões da sustentabilidade.

Nas análises dos indicadores da dimensão social, o Banco do Brasil é o que apresenta maior aderência com $7 \%$, em segundo lugar o Bradesco com 4,8\% e em seguida o Itaú Unibanco com 2,9\%. Na categoria da dimensão ambiental, o Banco do Brasil também é a instituição que apresenta maior aderência com $4 \%$, seguido do HSBC e Santander ambos com 2,6\%.

No comparativo entre as instituições financeiras nacionais (Banco do Brasil, Bradesco e Itaú Unibanco) e multinacionais (Citibank, HSBC e Santander), observa-se grande dispersão dos dados, não possibilitando estabelecer nenhum padrão de comportamento por esta variável.

A Tabela 2 apresenta a classificação dos indicadores econômicos das instituições financeiras. 
Tabela 2 - Classificação dos indicadores econômicos das instituições financeiras.

\begin{tabular}{lccccccc}
\hline Indicadores Econômicos & $\begin{array}{c}\text { Banco do } \\
\text { Brasil }\end{array}$ & Bradesco & Citibank & HSBC & $\begin{array}{c}\text { Itaú } \\
\text { Unibanco }\end{array}$ & $\begin{array}{c}\text { Santander } \\
\text { Total } \\
\text { Geral }\end{array}$ \\
\hline Desempenho Económico & 2 & 2 & 3 & 3 & 2 & 3 & 15 \\
Impactos Econômicos & 2 & 2 & 2 & 1 & - & 1 & 8 \\
Indiretos & 1 & 1 & - & - & - & 1 & 3 \\
Presença no Mercado & 5 & 5 & 5 & 4 & 2 & 5 & 26 \\
\hline Total Geral & 5 & & & & & & \\
\hline
\end{tabular}

Fonte: dados da pesquisa investigados e selecionados pelos autores em São Paulo SP: 2014.

A Tabela 2 apresenta os indicadores econômicos divididos em três categorias: desempenho econômico, impactos econômicos indiretos e presença no mercado. O Banco do Brasil, o Bradesco e o Santander, apresentaram indicadores nas três categorias. O Citibank e o HSBC não apresentaram a presença de mercado, enquanto o Itaú
Unibanco apresentou apenas o desempenho econômico. Destaca-se também que o Itaú Unibanco apresentou apenas dois indicadores econômicos, valor este bastante inferior ao das demais instituições financeiras. $\mathrm{Na}$ sequência a Tabela 3 apresenta a classificação dos indicadores sociais das instituições financeiras.

Tabela 3 - Classificação dos indicadores sociais das instituições financeiras.

\begin{tabular}{|c|c|c|c|c|c|c|c|}
\hline Indicadores Sociais & $\begin{array}{c}\text { Banco } \\
\text { do } \\
\text { Brasil }\end{array}$ & Bradesco & Citibank & HSBC & $\begin{array}{c}\text { Itaú } \\
\text { Unibanco }\end{array}$ & Santander & $\begin{array}{l}\text { Total } \\
\text { Geral }\end{array}$ \\
\hline Comunicações de Marketing & 1 & 2 & - & 2 & 1 & 2 & 8 \\
\hline Comunidade & 1 & 1 & - & - & - & 1 & 3 \\
\hline Concorrência Desleal & - & - & - & 1 & 1 & - & 2 \\
\hline Conformidade & 2 & 2 & 1 & 2 & - & 1 & 8 \\
\hline Corrupção & 3 & 1 & 3 & 3 & 2 & 3 & 15 \\
\hline Direitos dos Povos Indígenas & 1 & - & - & - & - & - & 1 \\
\hline $\begin{array}{l}\text { Diversidade e Igualdade de } \\
\text { Oportunidades }\end{array}$ & 2 & 2 & 2 & 1 & - & 2 & 9 \\
\hline Emprego & 2 & 3 & 2 & 2 & 2 & 2 & 13 \\
\hline Formação e Educação & 3 & 2 & 2 & 3 & 2 & 3 & 15 \\
\hline $\begin{array}{l}\text { Liberdade de Associação e } \\
\text { Acordo de Negociação Coletiva }\end{array}$ & 1 & 1 & - & - & - & - & 2 \\
\hline Não-discriminação & 1 & - & 1 & 1 & - & 1 & 4 \\
\hline Políticas Públicas & 1 & - & 1 & 2 & - & 2 & 6 \\
\hline $\begin{array}{l}\text { Práticas de Investimento e de } \\
\text { Aquisições }\end{array}$ & 3 & 1 & 2 & 3 & 1 & 3 & 13 \\
\hline Práticas de Segurança & - & - & - & - & - & 1 & 1 \\
\hline Privacidade do Cliente & - & 1 & - & 1 & 1 & 1 & 4 \\
\hline $\begin{array}{l}\text { Relações entre Funcionários e } \\
\text { Administração }\end{array}$ & 1 & 1 & 1 & - & - & - & 3 \\
\hline $\begin{array}{l}\text { Rotulagem de Produtos e } \\
\text { Serviços }\end{array}$ & 2 & 3 & 1 & 3 & 1 & 3 & 13 \\
\hline Saúde e Segurança do Cliente & - & - & - & 1 & 1 & 1 & 3 \\
\hline
\end{tabular}




\begin{tabular}{lccccccc} 
Segurança e Saúde no Trabalho & 4 & 1 & 1 & - & 3 & 4 & 13 \\
Social & 8 & 4 & - & - & 1 & 3 & 16 \\
Trabalho Forçado e Escravo & 1 & - & 1 & 1 & - & 1 & 4 \\
Trabalho Infantil & 1 & 1 & 1 & 1 & - & 1 & 5 \\
\hline Total Geral & 38 & 26 & 19 & 27 & 16 & 35 & 161 \\
\hline
\end{tabular}

Fonte: dados da pesquisa investigados e selecionados pelos autores em São Paulo SP: 2014.

A Tabela 3 mostra os indicadores de aspetos sociais, na qual é possível observar um volume e uma diversidade de aspectos maiores no comparativo com as dimensões econômica e ambiental. É possível classificar as instituições em três grupos distintos. $\mathrm{O}$ com maior quantidade de Indicadores composto pelo Banco do Brasil (38) e o Santander (35), o grupo intermediário com o Bradesco (26) e o HSBC (27) e o grupo com menor quantidade de indicadores composto pelo Citibank (19) e o Itaú Unibanco (16). Destaca-se que neste critério é possível observar equilíbrio entre as instituições nacionais e as internacionais, pois em cada um dos grupos há uma instituição nacional e uma internacional. Os indicadores sociais de: Corrupção, Diversidade e Igualdade de Oportunidades, Emprego, Formação e Educação, Práticas de Investimento e de Aquisições, Rotulagem de Produtos e Serviços, foram apresentados por todas as instituições financeiras, o que possibilita ações de comparação de desempenho. A classificação dos indicadores ambientais das instituições financeiras esta na Tabela 4.

Tabela 4 - Classificação dos indicadores ambientais das instituições financeiras.

\begin{tabular}{|c|c|c|c|c|c|c|c|}
\hline $\begin{array}{l}\text { Indicadores } \\
\text { ambientais }\end{array}$ & $\begin{array}{c}\text { Banco do } \\
\text { Brasil }\end{array}$ & Bradesco & Citibank & HSBC & $\begin{array}{c}\text { Itaú } \\
\text { Unibanco }\end{array}$ & Santander & $\begin{array}{l}\text { Total } \\
\text { Geral }\end{array}$ \\
\hline Água & 2 & - & 2 & 2 & 1 & 1 & 8 \\
\hline Ambiental & 4 & 2 & - & - & 1 & - & 7 \\
\hline Biodiversidade & 1 & - & - & - & 1 & - & 2 \\
\hline Conformidade & - & 1 & - & - & - & - & 1 \\
\hline $\begin{array}{l}\text { Emissões, Efluentes } \\
\text { e Resíduos }\end{array}$ & 5 & - & 3 & 4 & 4 & 6 & 22 \\
\hline Energia & 5 & - & 3 & 3 & 2 & 4 & 17 \\
\hline Geral & 1 & - & - & 1 & 1 & - & 3 \\
\hline Materiais & 2 & - & - & 2 & 1 & 1 & 6 \\
\hline Produtos e Serviços & 1 & 1 & - & 1 & - & 1 & 4 \\
\hline Transporte & 1 & 1 & - & 1 & - & 1 & 4 \\
\hline Total Geral & 22 & 5 & 8 & 14 & 11 & 14 & 74 \\
\hline
\end{tabular}

Fonte: dados da pesquisa investigados e selecionados pelos autores em São Paulo SP: 2014.

A atenção com a dimensão ambiental é observada em todas as instituições financeiras. O Banco do Brasil é o que apresenta a maior quantidade de indicadores (22) se destacando dos demais. O HSBC e o Santander aparecem em segundo lugar com
14 indicadores. O Bradesco é o que apresenta menor quantidade de indicadores, apenas cinco. Destaca-se que nenhuma das instituições analisadas apresenta todos os indicadores, o Banco do Brasil foi o mais 
aderente, no entanto não apresenta o indicador de conformidade.

Os principais aspectos relacionados aos indicadores ambientais estão classificados como Emissões, Efluentes e Resíduos com um total de 22 indicadores, na sequência a energia com 17 indicadores e em terceiro a água com oito indicadores.

$\mathrm{Na}$ Tabela 5 encontra-se a quantidade total de indicadores apresentados por cada instituição financeira.

Tabela 5 - Total de indicadores por instituição financeira

\begin{tabular}{lc}
\hline Empresas & Contagem de Aderência \\
\hline Banco do Brasil & 139 \\
Bradesco & 86 \\
Itaú Unibanco & 75 \\
Santander & 70 \\
HSBC & 61
\end{tabular}

Citibank 35

Fonte: dados da pesquisa investigados e selecionados pelos autores em São Paulo SP: 2014.

Em análise a Tabela 5, identificou-se que o total de indicadores de sustentabilidade em suas três dimensões é superior nas três instituições nacionais, enquanto que as três instituições internacionais aparecem na sequência. Este perfil mostra maior interesse das instituições brasileiras em apresentar seu desempenho na forma de indicadores, no entanto, os mesmos ainda se apresentam distantes dos recomendados pelo GRI, conforme relatado na Tabela 1 , apresentada anteriormente.

$\mathrm{Na}$ Tabela 6 observam-se apenas os indicadores aderentes ao GRI de cada uma das instituições analisadas.

Tabela 6 - Total de indicadores das instituições financeiras aderentes ao GRI

\begin{tabular}{lccccccc}
\hline Indicadores & $\begin{array}{c}\text { Banco do } \\
\text { Brasil }\end{array}$ & Santander & HSBC & Bradesco & Citibank & Itaú Unibanco & Total Geral \\
\hline Social & 38 & 35 & 27 & 26 & 19 & 16 & 161 \\
Ambiental & 22 & 14 & 14 & 5 & 8 & 11 & 74 \\
Econômico & 5 & 5 & 4 & 5 & 5 & 2 & 26 \\
\hline Total Geral & 65 & 54 & 45 & 36 & 32 & 29 & 261 \\
\hline
\end{tabular}

Fonte: dados da pesquisa investigados e selecionados pelos autores em São Paulo SP: 2014.

A análise da Tabela 6 mostra o Banco do Brasil como à instituição que possui mais indicadores em cada uma das dimensões da sustentabilidade e também no total de indicadores aderentes ao GRI. Destaca-se que não é possível observar o predomínio das instituições nacionais sobre as internacionais, conforme evidenciado na Tabela 5. Destacase que o Banco do Brasil (65 indicadores) possui mais que o dobro dos indicadores que o Itaú Unibanco (29 indicadores). Esta diferença não possui uma justificativa operacional, uma das possibilidades de explicação desta diferença é que o Banco do Brasil é uma instituição pública, enquanto o Itaú Unibanco é uma instituição privada. Partindo desta análise, seria possível discutir se instituições públicas possuem maior interesse de divulgar seus resultados na forma de indicadores e com maior aderência ao modelo do GRI respectivamente.

A Tabela 7 apresenta os indicadores de Perfil e Governança e os setoriais, que não pertencem a TBL, mas que é objeto de atenção do GRI.

Tabela 7 - Indicadores Perfil e Governança e Setoriais

\begin{tabular}{llll}
\hline Empresas & Perfil e Governança & Setoriais & Total Geral \\
\hline
\end{tabular}




\begin{tabular}{lccc}
\hline Banco do Brasil & 58 & 16 & 74 \\
Bradesco & 34 & 16 & 50 \\
Citibank & & 3 & 3 \\
HSBC & & 16 & 16 \\
Itaú Unibanco & 34 & 12 & 46 \\
Santander & & 16 & 16
\end{tabular}

Fonte: $\overline{\text { dados da pesquisa investigados e selecionados pelos autores em São Paulo SP: }} 2014$.

Analisando os indicadores de Perfil e Governança e setoriais identifica-se que o Banco do Brasil é o que apresenta maior volume de indicadores (74) no agregado. $\mathrm{O}$ Banco do Brasil também é o que apresenta maior quantidade de indicadores de Perfil e Governança (58) e Setoriais (16). As instituições nacionais apresentam perfil bastante distinto das internacionais. O Banco do Brasil (58), o Bradesco (34) e o Itaú Unibanco (34) - instituições nacionais - foram as únicas a apresentar indicadores de Perfil e Governança. Evidencia-se uma maior atenção das instituições nacionais em relatar o perfil e a governança para o mercado de capitais.

A análise combinada dos dados apresentados nas tabelas evidencia discreto interesse das instituições financeiras em publicar seu desempenho na forma de indicadores aderentes ao GRI. No entanto, apesar da baixa aderência é possível observar a existência dos relatórios e por consequência do interesse das instituições em divulgar seu desempenho sustentável, conforme proposto por Benites e Polo (2013). Destaca-se a que baixa quantidade de indicadores aderentes ao GRI não possibilita evidenciar a plenitude das ações empresariais voltadas para a sustentabilidade conforme aponta Marimon et al.(2012). Condição esta que inibe os stakeholders de estabelecer pleno conhecimento da sustentabilidade das empresas conforme proposta do relatório do GRI, apontado por Benites e Polo (2013) como o mais completo e mundialmente difundido.
A baixa adesão das instituições financeiras aos indicadores econômicos do GRI, não possibilita a compreensão do desempenho econômico de forma sustentável das instituições financeiras conforme propõe Bellen (2005), ao sinalizar que os indicadores são importantes para a compreensão do significado operacional do conceito de Desenvolvimento Sustentável. Não auxiliando no processo de conhecimento da realidade conforme propõe Bessermam (2003). $\mathrm{Na}$ sequência são apresentadas as considerações finais desta pesquisa.

\section{Considerações finais}

A análise dos dados da pesquisa revela que as instituições financeiras divulgam para a sociedade em geral seu desempenho por meio de relatórios contendo indicadores de sustentabilidade que expressam a sua gestão. Apesar da existência de indicadores de sustentabilidade foi possível evidenciar que eles se apresentam em quantidade inferior ao proposto pelo GRI, e ainda se identificou um conjunto de indicadores, que são divulgados, e não apresentam aderência a proposta do modelo de relatório.

O método utilizado na investigação se mostrou adequado ao objetivo especifico, pois os relatórios estavam disponíveis para consulta e apresentavam os itens de investigação. Vale pontuar que, pela quantidade e diversidade de informações contidas nos relatórios de sustentabilidade 
pesquisados, é possível afirmar que este tipo de documento se configura em uma importante ferramenta, não só para evidenciar as informações socioambientais aos stakeholders, mas, sobretudo, para uma eficiente e eficaz gestão estratégica da sustentabilidade empresarial.

Observou-se que as instituições nacionais apresentam um maior volume de indicadores em relação às instituições internacionais e ainda uma maior atenção ao indicador Perfil de Governança. Vale destacar que este indicador em particular não é utilizado por nenhuma instituição internacional.

As dimensões social, ambiental e econômica da sustentabilidade recebem proporções diferentes de indicadores pelas instituições financeiras. A dimensão social é a que possui maior número de indicadores de controle e maior aderência a proposta do relatório do GRI. $\mathrm{Na}$ segunda posição aparece a dimensão ambiental e por último a dimensão econômica. A dimensão econômica aparece com um pequeno volume de indicadores e com baixa aderência ao relatório do GRI. No entanto, observou-se que o tripé da sustentabilidade foi utilizado invariavelmente, pois incluem as dimensões econômica, social e ambiental. Nesse sentido, corroboram com as proposições dos autores utilizados na plataforma teórica.

Dentre as instituições financeiras o Banco do Brasil se destaca por disponibilizar em seu relatório o maior número de indicadores de sustentabilidade e na maioria dos casos apresentarem maior aderência à proposta do GRI.

A análise de apenas seis instituições financeiras se apresenta como uma limitação deste estudo, pois há outras instituições atuantes no Brasil que poderiam incorporar a amostra de estudo. No entanto, apesar desta limitação o estudo apresenta validade por abordar uma amostra significativa e diversificada.

Futuros estudos que analisem a evolução, ou não, de indicadores de sustentabilidade nas instituições financeiras, se mostra bastante viável, pois colaboraria para a aderência das instituições financeiras ao GRI.

\section{Bibliografia}

AMATO NETO, J. Sustentabilidade e Produção. São Paulo: Editora Atlas: 2011.

ANDRADE, M. M. Como preparar trabalhos para cursos de pós-graduação: noções práticas. 5. ed. São Paulo: Editora Atlas, 2002.

BABBIE, E. The practice of social research. 5 ed. Califórnia: Wadsworth, 1989.

BASSETTO, L. I. A incorporação da responsabilidade social e sustentabilidade: um estudo baseado no relatório de gestão 2005 da companhia paranaense de energia COPEL. Gestão \& Produção, v. 17, n. 3, 2010 .

BECKER, J. Making sustainable development evaluations work. Sustainable Development, Chichester, v. 2, n. 4, p. 200211, nov. 2004.

BELLEN, H. M. Indicadores de sustentabilidade: uma análise comparativa. 2. ed. Rio de Janeiro: FGV, 2005. 
BELLEN, H. M. V. Indicadores de sustentabilidade: uma análise comparativa. Rio de Janeiro: FGV, 2007.

BENITES, L.L.L.;POLO, E.F.; A Sustentabilidade como ferramenta estratégica empresarial: governança corporativa e aplicação do triple bottom line na Masisa. Rev. Adm. UFSM, Santa Maria, v. 6, Edição Especial, p. 827-841, Mai. 2013

BESSERMAN, S. Meio ambiente no século 21: indicadores. Rio de Janeiro: Sextante, 2003.

BM\&F BOVESPA. Índice de sustentabilidade empresarial: ISE. Disponível em:

<http://www.bmfbovespa.com.br/indices/

ResumoBoletimISE.aspx?eIdioma $=$ pt-br $>$.

Acesso em: 14 abr. 2011.

BOVESPA - Bolsa de Valores de São Paulo. Índice de sustentabilidade empresarial. Disponível

em:<http://www.bovespa.com.br/Mercado /RendaVariavel/Indices/FormConsulta ApresentacaoP.asp?Indice $=$ ISE $>. \quad$ Acesso em: 20 mar. 2009.

BROWN, H. S., DE JONG, M., LEVY, D. L. Building institutions based on information disclosure: lessons from GRI's sustainability reporting. Journal of Cleaner Production, v. 17, n. 6, p. 571-580, 2009.
CARROLL, A. B . Corporate social responsibility. Business and Society, v. 8, n.3, p. 268-295, set. 1999.

CERVO, A. L.; BERVIAN, P. A. Metodologia científica. 5. ed. São Paulo: Prentice Hall, 2002.

CSD. Indicators of sustainable development: guidelines and methodologies. Comission on Sustainable Development, 2002.

DEPONTI, C. M. Estratégias para construção de indicadores para avaliação da sustentabilidade e monitoramento de sistemas. Revista Agroecologia e desenvolvimento sustentável. Porto Alegre: Emater/RS, v.3, n. 4, out/dez. 2002.

GIL, A. C. Como elaborar projetos de pesquisa. 5 ed. São Paulo: Atlas, 2010.

GIL, A. C. Métodos e técnicas de pesquisa social. 6. ed. São Paulo: Atlas, 2008.

GRI - GLOBAL REPORTINGINIATIVE. Diretrizes para relatório de sustentabilidade. versão 3.0. São Paulo: GRI, 2006a.

GRI - GLOBAL REPORTING INIATIVE. Níveis de aplicação da GRI. 2006b. Disponível em: <http://www.globalreporting.org/NR/rdon lyres / 4855C490-A872-4934-9E0B8C2502622576/5273/AL_G3_Portuguese_ BR.pdf> Acesso em: 10 abr. 2014.

GRI - GLOBAL REPORTINGINIATIVE. Disponível em: <http:// 
www.globalreporting.org/Home/WhatWeD oPortuguese.htm>. Acesso em: 13 ago. 2009. GRI - GLOBAL REPORTING INITIATIVE. Sustainability reporting guidelines. Disponível em: $<$ http://www.globalreporting.org $>$. Acesso em: 18 mar. 2014.

HARDI, P.; ZDAN, T. J. The dashboard of sustainability. Winnipeg: IISD, 2000.

HILSON, G.; BASU, A. J. Devising indicators of sustainable development for the mining and minerals industry: an analysis of critical background issues. International Journal of Sustainable Development and World Ecology, v. 10, n. 4, p. 319-331, dec, 2003.

INSTITUTO BRASILEIRO DE ANÁLISES SOCIAIS E ECONÔMICAS. Balanço social. Disponível em: <http://www.ibase.br> Acesso em: 24 abr. 2009.

INSTITUTO ETHOS DE EMPRESAS E RESPONSABILIDADE SOCIAL. Pesquisa geral no site. Disponível em: $<$ http://www.ethos.org.br>. Acesso em: 05 mar. 2009.

KRAJNC, D.; GLAVIC, P. Indicators of sustainable development. Clean Technology Environment Policy, n. 5, p. 279-288, 2005. LEVY, D. L.; SZEJNWALD-BROWN, H.; DE JONG, M. The Contested politics of corporate governance the case of the global reporting initiative. Business \& Society, v. 49, n. 1, p. 88-115, 2010.

LONGARAY, A. A. et al. Como elaborar trabalhos monográficos em contabilidade: teoria e prática. São Paulo: Atlas, 2003.

MACKEY, A. T. B.; MACKEY J. B.; BARNEY. Corporate social responsibility and firm performance: Investor relations and corporate strategies. Academy of Management Review, v. 32, p. 817-835, 2007.

MARIMON, F. et al. The worldwide diffusion of the global reporting initiative: what is the point? Journal of Cleaner Production, v. 33, p. 132-144, 2012.

MEADOWS, D. Indicators and information systems for sustainable development. A Reportto the Balaton Group. The Sustainability Institute, Hartland Four Corners, VT, 1998.

MOLDAN, B.; BILLHARZ, S. Sustainability indicators: report of the project on indicators of sustainable development. Chichester: John Wiley \& Sons, 1997.

OLIVEIRA, M. C. et al. Disclosure of social information by Brazilian companies according to United Nations indicators of corporate social responsibility. Revista Contabilidade e Finanças, São Paulo, v. 20, n. 51, 2009. Disponível em: $<$ http://www.scielo.br/scielo.php?script=sc i_arttext\&pid=S1519- 
70772009000300008\&lng=pt\&nrm $=$ iso $>$. Acesso em: 06 jan. 2011.

PORTER, M.; KRAMER, M. Strategy and Society: the link between competitive advantage and corporate social responsibility. HBR Spotlight, Harvard Business Review. December 2006.

RAGAS, A. M.J.; KNAPEN, M. J.; VAN DE HEUVEL, P. J. M.; EIJKENBOOM, R. G. F.T.M.; BUISE, C. L.; VAN DE LAAR, B.J. Towards a sustainability indicator for production systems. Journal of Cleaner Production, v. 3, n. 1-2, p. 123-129, 1995.
RUDIO, F. V. Introdução ao projeto de pesquisa científica. 31. ed. Petrópolis: Vozes, 2003.

TEIXEIRA, E. A.; NOSSA, V.;FUNCHAL, B. O índice de sustentabilidade empresarial (ISE) e os impactos no endividamento e na percepção de risco. R. Cont. Fin. - USP, São Paulo, v. 22, n. 55, p. 29-44, jan./fev./mar./abr. 2011.

TINOCO, J. E. P. Balanço social e relatório de sustentabilidade. São Paulo: Atlas,2010. 